\title{
Filipino English Teachers in Japan: "Nonnativeness" and the Teaching and Learning of English
}

\author{
Nelia G. Balgoa \\ Department of English, Mindanao State University-Iligan Institute of Technology, Philippines
}

\begin{abstract}
A feature of the Japan Exchange and Teaching (JET) Program, which aims to internationalize Japan and to improve the English-speaking ability of its students, is the hiring of Assistant Language Teachers (ALTs) who are described by the Japanese government as native-level speakers of English working in Japanese classrooms. By using critical applied linguistic which focuses on questions of power, difference, access and domination in the use of the English language (Pennycook, 2001), this paper examines the motivations of the Filipino teachers as ALTs, the processes of international teacher recruitment and how their 'nonnativeness' reconfigure their identity as nonnative English speaker teachers (NNESTs) and Filipino migrants. Data from in-depth interviews and focus group discussions of Filipino ALTs and Japanese teachers show that English is both motivation and vehicle for migration and settlement for the Filipino teachers. "Nonnativeness" requires from them reconfiguration of their identity which entails them to sound native, counteract perceived forms of discrimination and assess their roles in the spread and use of English. This "nonnativeness" is a repudiation of their skills and qualifications as English teachers thus, paving the way for an interrogation of language ideologies, and of linguistic and racial identities.
\end{abstract}

Index Terms—nativeness, Filipino migration, English language learning

\section{INTRODUCTION}

The teaching and learning of English has never been a contentious discourse in the field of social science because of the need of the globalized world to communicate. The academic terms, "lingua franca", "international language", "world language" have been used to describe the crucial role of the English language in terms of reach, usage and influence. These concepts emerged from studies and approaches of scholars, practitioners and academicians who immersed themselves in the study of the language, from its development, structure, usage and applicability. The field of applied linguistics for example, has focused, over the years, especially in developing and former colonized countries, to the policies and pedagogy in the teaching of the language. In multilingual societies, particularly where English is the second language, code mixing, code switching and translation studies have shown the complexities and issues of communication and language studies. Postcolonial studies view English as a continuing consequence of Western domination, imperialism and neoimperialism influencing the world view, culture and the social and political conditions of former colonies.

A much important issue in the study of English is its global spread. Kachru's (1992) World Englishes (WE) has dominated the discussion in the past twenty years, problematizing the way varieties of English and the norms of correctness and standardization is approached and viewed. Critics of Kachru's Three-Circle Model of WE argue that it has failed to address the other factors such as the dynamics of power, accessibility and inequality in the spread of language (Bruthiaux, 2003; Pennycook, 2017). Moreover, the model is often associated with operating along national and class lines such that it has failed to address the gaps and in-betweens between circles (Martin, 2014).

English as a lingua franca (ELF) is a more recent approach to the spread of English. In ELF, English is viewed as "the common language, a meeting ground" when non-native speakers of English communicate. Like the World Englishes paradigm, it interrogates varieties of English which emerge and develop from multilingual societies. ELF challenges deeply entrenched notions of what is standard, correct English by focusing on the use of English in local, specific contexts. Moreover, it questions the appropriateness of the native speaker (NS) model in countries where English is considered as a second language rather than a foreign language. It broadens the scope of the WE English by considering the local varieties of English not represented in the circles.

The spread of English globally and its use as ELF has been the precursor of countries in the outer circle of Kachru's model to institutionalize the learning and teaching of English. Countries like Japan, in order to be at par with other highly developed countries and to "internationalize" its citizenship, mandated the learning of English in its educational system more aggressively. In 2001, the Ministry of Education, Culture, Sports, Science and Technology (MEXT) implemented the "Rainbow Plan", an educational reform for the $21^{\text {st }}$ century. This plan made compulsory the learning of English in starting in elementary level, making it much earlier than previously requiring it in the junior high school. 
In order to facilitate this reform, the Japan Exchange and Teaching (JET) Program was conceived in 1987 to promote international exchange and language education between Japan and other nations. It was established by local authorities, MEXT, and the Ministries of Internal Affairs and Communication and Foreign Affairs. According to McRostie (2017) with nearly 65,000 people from 65 countries participating since its modest start, the program has grown into one of the world's largest international exchange programs. Its goal is to promote international understanding through English programs and it is the hope of the participating Japanese government agencies that the students will then carry what they learned in school to their adult lives, thereby benefiting the country as a whole (Ohtani, 2010).

One of the main features of the JET Program is the hiring of Assistant Language Teachers (ALTs) who will assist Japanese English teachers in their classrooms and in the supervision of their English classes. In addition, JET dispatches ALTs to public elementary and high schools in local communities. This aggressive move made by the Japanese government aims to make their students functional in English in five years (Ohtani, 2010) through exposing Japanese students to an English-speaking environment and for the ALTs to provide expertise in terms of language proficiency to Japanese teachers.

Although it was specified by the screening committee, the Council of Local Authorities for International Relations (CLAIR), that ALTs must be native speakers, a great number ALTs are Filipino teachers, hired through recruiting agencies or directly by the Board of Education of Japan. This reveals that the concept of nativeness and the spread and teaching of English is a highly complex phenomenon, often connected to cultural, political and ideological forces. The binary opposition of nativeness/nonnativeness within the context of English language and learning in Japan is made possible and apparent within the hiring of Filipino teachers who participate in the dynamics of international migration and the spread of English in this highly globalized world.

This paper therefore is an attempt to explore and analyze the motivations of the Filipino teachers to migrate and teach English in Japan and how their "nonnativeness" shapes and reshapes their identity as nonnative English speaker teachers (NNESTs) and Filipino migrants in Japan thereby providing evidence that the spread of English, its learning and teaching is very much influenced by market demand, desires, ideological forces and international migration.

\section{CRITICAL THEORY}

According to Pennycook (1998, 2017), the spread of English cannot be disassociated and understood without considering the cultural, political and ideological forces which shape its development. This argument stems from his criticisms on the WE and ELF models which, according to him failed to address the fundamental questions of power and inequality. Rejecting the necessity of understanding historical imperialism as a prerequisite in understanding the domination of English, Pennycook rather argues that English is embedded in economic desires and that the demand for the language is part of a larger picture of change, globalization, access and longing, the last being a consequence of postcolonial ethos highly influenced by the movement of people across nation states.

The idea of nativeness within English Language Teaching (ELT) domains and disciplines interrogates the notion of "correct", "standard" English. This has become more debatable as within the context of international migration, making societies and cultures multidimensional and multilingual. Contrary to what Jenkins (2006) claims, that the ELF paradigm does not subscribe to a single, monolithic English but proposes that participants of communication processes be equipped with linguistic repertoire for use which is intelligible and appropriate for English users who come from various language orientation and background, other language scholars argue that nativeness brings it with it a discourse of exclusion, discrimination or even rationalization for interventions (Pennycook, 1998; Kabel, 2009). This becomes more apparent as the need for English has become a global market, with the demand for teachers increasing and thus there is a divide between native-English-speaking teachers (NESTs) and non-native-English-speaking teachers (NNESTs). This makes the teaching and learning of English not only a question of language studies but how this intersects with the notion of race and identity.

Holliday (2006) defines native-speakerism as pervasive ideology that places the native speaker as the source of "Western culture" and therefore brings into fore the question of inequalities in English Language Teaching (ELT). He elucidates this further by claiming that native-speakerism trivializes the abilities of NNESTs and students to adequately respond to and be engaged in classroom activities which is patterned after Western pedagogies (Kusaka, 2013). This ideology does not acknowledge the cultural background of a teacher or student as a re/source of learning and knowledge.

Within this context, this article takes into consideration the Filipino ALTs in Japan, and argues that their experiences as migrants and English teachers in a country where English is taught as a foreign language, and where the need for it is not for domestic consumption but rather for internationalization (Kobayashi, 2007), reflect what Pennycook claims that the global spread of English is not neutral nor given but rather an interplay of power and people's desires and dreams. In this context, the Filipino ALTs and how they reconfigure their identity as migrants and NNTEs in Japan is part of political and cultural practice and an examination of their roles as agents in the spread of English and its political implications.

\section{Methodology}


Data from this research were gathered through in-depth interviews of 18 Filipino ALTs who worked in various public and elementary high schools in various areas of Japan. Two focus group discussions were conducted in Oyama City, Tochigi Prefecture, and were participated in by three ALTs in each session.

Interviews were conducted mostly in English, with ALTs switching to Filipino in most cases and lasted from 40 minutes to one hour and a half. They also code mixed with Japanese especially for words which they deemed have no English or Japanese equivalents. The interviews started with basic questions such as age, marital status, educational background, their length of stay in Japan so as to get the profiles of the informants. The overarching questions of the interview pertained to the following:

1. The processes of their entries to Japan and their reasons and motivations of becoming ALTs;

2. The challenges and hardships of being NNESTs in Japan and

3. Their opinions on the strengths and weaknesses of English learning and teaching in Japan.

A detailed questionnaire, which extracts their impressions of Filipino ALTs as NNESTs, was also distributed to four Japanese supervisors. The researcher was not able to observe classes but was able to watch a video of a class demonstration of one of the informants during a Board of Education visit to his school.

\section{B. The Informants}

Of the 18 Filipino ALTs that were interviewed, nine taught in high school and one of them was promoted to a supervisory level. Nine others taught in elementary level at the time of the interview. One, after follow up interviews transferred to high school. Of these 18, four entered Japan on student visa (all Japanese Government scholars), five as Japanese descendants, two on Japanese spouse visa, three on working visa, one on entertainment visa, two on working visa and one on missionary visa.

The informants have been ALTs on an average of 3-6 years; one informant has just taught for a year in an elementary school at the time of the interview while two has been an ALT for 8-10 years. Six of them come from Mindanao and the rest consider Luzon as their home. Eight of the informants teach in public schools in Tochigi, four in Osaka, three in Nagoya, two in Osaka and one in Kobe.

Of the Japanese supervisors who were interviewed, one is already retired and the three are in their 40s. Three claimed that they are better in Japanese than in English while one said he is "quite" proficient. Three supervisors answered the questionnaire in Japanese while one answered it in English.

\section{RESULTS AND DISCUSSION}

\section{A. The Filipino ALTs in Japan}

ALTs are considered to be cultural ambassadors and are to promote internationalization and cultural exchange in the grassroots level. As part of the Japan Exchange Teaching Program, they are expected to assist in classes taught by Japanese Teachers of English (JET) and in the preparation of teaching materials and participate in extra-curricular activities with students.

As of 2017, there are 5,044 ALTs in Japan from 66 countries. Of this number, 87 are Filipinos. 1 For the year 2018, 40 Filipinos were accepted in the program. The ALTs' contract is usually for one year which then can be renewed for five years.

In its inception, the JET Program is the main source of ALTs in Japan. The program is usually facilitated by the embassies of Japan in participating countries, where upon acceptance, they undergo pre-departure orientation and seminar and observe and visit classes in Japanese Embassy attached schools. Participating local governments of Japan cover the salaries and airfare of the ALTs but with the increasing expenses entailed by the program, the local governments have shifted to private and outsource companies to hire and dispatch ALTs to their respective areas. Since the Philippines joined the JET Program only in 2013, all Filipino ALTs interviewed except for two went through the second process, since all of them entered Japan in different visa categories and applying for ALT was an option to extend their stay in Japan legally. Since most of them have stayed for more than 5 years in Japan, their reapplication process is through dispatch companies or to the local Board of Education of Japan.

Not all Filipino ALTs have teaching degrees and experience and this is also true for ALTs from other countries. Browne as cited by Ohtani (2010) claims that the JET program is fraught with inadequacies and one of these is the poor eligibility criteria in terms of educational and pedagogical background of the hired teachers. Insufficient training and inadequate preparation of the teachers were also cited by Ohtani (2010) as problems encountered in the implementation of the said program.

Of the 18 ALTs interviewed in this study, only six have a background in teaching, having taught in high schools, kindergarten schools and in university before going to Japan but none have background in teaching English either as a second language or foreign language. One is not even a high school graduate but claimed to have become proficient in the language through constant practice and interaction with English speaking acquaintances and friends.

\footnotetext{
${ }^{1}$ Retrieved. From http://jetprogramme.org/en/countries/. This number pertains to ALTs who applied through the JET program and does not include the ALTS dispatched through the local Boards of Education and private companies.
} 


\section{B. Filipino ALTs as Migrants: Economics, Not Internationalization}

The JET program was conceived to promote mutual understanding between Japan and other nations through foreign language education and foreign exchange at the community level. Participants of the said program were expected to be actively engaged in activities that promote internationalization and cultural exchange.

None of these was in the minds and aspirations of the Filipino ALTs when they applied for the position. Validating previous studies on the push factors on why Filipinos migrate, the informants expressed that their motivations for becoming ALTs in Japan is for economic reasons. Dennis ${ }^{2}$, for example, is a head teacher dispatched by a big private company in high schools in Kobe area. As head teacher, he monitors other ALTs and reports directly to the company. He arrived in Japan as a researcher for a private company but when his contract ended and he still had two years remaining in his visa, his Japanese-Canadian friend encouraged him to apply as an ALT. Although he had taught Biology in a state university in the Philippines before coming to Japan, he considered himself inexperienced in teaching English. Dennis attributes his promotion to being a head teacher to his performance and his ability to get along well with others.

Two female informants, who are married to Japanese men, consider being ALTs as a strategy to be highly regarded by the Japanese society and their families. Aware that Filipino women are stereotyped as entertainers and domestic helpers in the country, Bea sees teaching English as an opportunity to improve her worth in the eyes of her family, especially her children. According to her, since English is much valued in Japan, being an ALT allows her to reconfigure her identity as a Filipino migrant married to a Japanese man in such a way that she becomes more valued by her children and her husband and gives her an upward social mobility in terms of social acceptance and financial gains. The same is true with Dency, who used to teach history classes in high schools in the Philippines before she met her Japanese husband and then migrated to Japan. After three years, she worked as a part-time teacher in a cram school and then applied as an ALT through the Board of Education. Being an ALT, according to Dency, allows her to be financially independent and help her family back in the Philippines and she "can hold her head high" among the relatives of her husband because "she is not the usual Filipina who came to Japan."

Dency and Bea's experiences are manifestations of what Fuwa and Anderson (2005) call "agency", which is the ability to make choices and become an active member of the society. English, in this sense, is a strategy for these two ALTs to exercise their agency and an attempt to assimilate into the Japanese society and in the process rectify the common stereotypes often attributed to Filipino women.

Pennycook's argument that English as an embodiment of longing and economic desires propelled by globalization is very much evident in the four ALTs that were interviewed. Three of them entered Japan as Japanese Government scholars and are therefore considered to be highly skilled and educated individuals. When their scholarships ended, they were resolute in staying in Japan, find a job in order to help their families in the Philippines. Leslie, for example, has a $\mathrm{PhD}$ degree in Technology from one of the best universities in Japan and yet had difficulties in being accepted in Japanese companies. Her last option was to be an ALT, a job which she considers as "not really aligned with her educational attainment yet decent enough" not to disappoint herself and her family. Lourd and Irish were both public school teachers in the Philippines but decided to resign from their jobs after their scholarships and applied to be ALTs. According to them, the economic gains make up for the loneliness of being away from their families. All have substantial economic investments in the Philippines made possible by their being ALTs.

The three consider English as their economic capital as Filipino migrants in Japan. Within the ALT working system however they have to reconfigure their aspirations and dreams as befitting their motivations in coming to Japan. Leslie, who has a PhD degree, considers being an ALT as "settling" because she could not find a space in IT companies while Lourd and Irish, both stable and recognized teachers in high schools back in the Philippines have to deal with the uncertainty whether their contracts will be renewed every year. But for these ALTs, their English proficiency allow them to "settle" lowering their expectations but at the same time making them feel empowered migrants in Japan because according to Lourd " at least we are not entertainers or domestic helpers".

Helen and Ivie's motivation in going to Japan is not their aspirations but those of their parents who entered Japan as "nikkei jin" or of second generation Japanese descent. Both girls studied in one of the best private universities in the Philippines, which they claim was made possible because of their parents' work in Japan. When they graduated, their parents wanted them to come and join them in the country and find jobs. Their parents' friends introduced the idea of being ALTs and they applied in the Japanese Embassy in the Philippines when they heard it was accepting applications. Not having enough teaching experience, they admitted having difficulty in adjusting to the profession especially with the language barrier and different culture, but they are convinced that as Filipino university graduates and with their proficiency in the English language, they are much better that other ALTs.

The experiences of the Filipino ALTs interviewed reflect not only their motivations of becoming English teachers but also how the language becomes an economic capital, an exercise of agency and an expression of longing and desires of migrants who need to reconfigure their identities and aspirations to be able to conform with the social expectations not only from their families in the Philippines but also how they can break away from the stereotyped notions of what Filipino migrants are perceived to be in Japan. In this sense, English and the ALT program of Japan reflects the

\footnotetext{
${ }^{2}$ No real names are used to ensure privacy.
} 
interplay between the processes of international migration and the spread of English, revealing incongruences of goals between the Filipino ALTs and the program.

\section{Filipino ALTS as Nonnative-English Speaking Teachers (NNESTs): Nonnativeness in English Teaching and Learning}

The Philippines prides itself of being an English-speaking country. Inherited from the colonization of the United States, English became one of the official languages and modes of instruction in all educational levels. English is fully entrenched in the way of life of most Filipinos; it is considered as a status symbol, the language of the educated. It is the language used in domains of communication that involves power and prestige (Bernardo, 2008). In most social and political institutions that affect and define the conduct of affairs and perspectives of the people, English is the language used. In the discourse of national identity and nationalism, English and its implications is still a wedge that divides the regions of the country, the socio-economic condition of its people and the fate of local languages. Despite a number of legislations and debate among scholars and government officials on the use of the English language, it is still, at this point in time, a potent tool for communication and a persistence presence in the educational system and the lives of millions of Filipinos.

An indication of this is the emphasis on the need of students to gain proficiency in English in order to be globally competitive. As a migrant sending country, the Philippines relies heavily on the remittances of the Filipinos working abroad to keep its economy afloat. Thus, English is seen as a distinct advantage for most Filipinos who hope to migrate and seek for opportunities outside the country.

Japan, and its need to internationalize, is seen then as a market and opportunity for highly educated, highly proficient in English Filipino migrants. It is also a country known for its predilection to learning the native and standard English and avoidance of varieties of English (Honna and Takeshita, 1998). This propensity and this essentialist view towards English by the Japanese populace, especially in education, has created this wide divide between native and nonnative teachers. San Jose and Ballescas (2010) in their study of 14 Filipino ALTs dispatched to different parts of the country, pointed out that one of the challenges and burdens faced by Filipino ALTs is not being considered as "native speakers" and of having "Asian accents". Thus, for the Filipino ALTs in this study, the workplace can be fraught with obstacles, hardships, adjustments and to a certain extent discrimination, which they attributed to a different education system and culture and largely to the fact that they are nonnative speakers of the language.

Studies on nonnative-English speaking teachers in Japan (NNESTs) are mostly phenomenological in approach; that is these are often reflective writings and emphasize mostly the personal experiences of ALTs themselves who are NNESTs (Muljadi, 2016; McRostie, 2017). San Jose and Ballescas (2010) also studied Filipino ALTs and their roles in promoting multiculturalism within and outside their classrooms. There is dearth of studies of placing these experiences in a wider political and social context and in the process understanding the ALT program and how the teaching and learning of English becomes a byproduct of the complexities of globalization and power relations affecting language use and teaching.

Accent is the most visible and discernible indication of nativeness and/or nonnativeness. Accent constructs identity; it can exclude or include a speaker in a speech community. For all informants, accent is one indicator which can be manipulated and, in the process, , allow them to reconfigure their identity. Ike, a 42-year old ALT who used to work in a non-government organization in the Philippines puts extra and conscious effort to sound American when teaching in Japanese classrooms. The reason according to him:

There are difficulties. They (Japanese teachers) were commenting on the accent. There were Japanese teachers concerned on the accent, trying to compare Asian accent and the native accent. I think we experienced being criticized for our Filipino English. Because there is a distinct, we have grammatical loopholes in English. When we make mistake, they say, "Is that how you say it in the Philippines?" I say, yes, that's how we say it in the Philippines.

Mihai, a 26-year old Filipino ALT of Japanese descent assigned in an elementary school in Kobe also feels the same way. For her, native speakers are more fortunate because they do not have to "practice" the language. According to her, for the native speakers, "It's in their blood, it's natural". Mihai realized that being nonnative is considered an inadequacy when she was corrected by the Japanese English Teacher (JET) which she assisted in front of the students and the students laughed. From there on, she would study the lessons ahead of time, practice the words to be taught repeatedly in front of a mirror and watched numerous Youtube videos for tutorial.

All informants expressed a certain pride and superiority when a Japanese teacher or student or even parents would comment that they sound American. Dennis, the only supervisor among the ALTs interviewed, said he did not have difficulty in acquiring the American accent since he grew up speaking and using the language and considers it to be his first language. According to him, many native speakers and Japanese alike are surprise that he is a Filipino because of his accent. He sees nothing wrong should the Japanese school system demand that they sound native since according to him, this is to "make them sound legitimate and competent". This is echoed by Ike who said that it is just proper to sound native in front of the students. Irish said that to sound native is their choice, so that they will be more convincing and believable. Leslie said it is not required by their schools nor the dispatch companies but she pressures herself to sound native so that students will respect her more.

Although the Filipino ALTs consider "to sound native" as a problem, they do not believe, however, that this is a form of discrimination. Since accent can be acquired and learned, they believe that this can surmounted. For them, accent is 
an achievable skill which they can reconfigure to be considered as native speakers which is more acceptable to their students and colleagues than their teaching qualifications and experience. They are convinced that native accent is a social capital and attribute which they can fully utilize to further their career.

The Council of Local Authorities for International Relations (CLAIR), the body which screens and implements the JET Program specifies that ALTs must be native speakers. The Board of Education of Japan, however, according to the informants, does not have a policy that all NNESTs should sound American in the classroom. This is validated by the three supervisors who were interviewed. These Japanese supervisors agreed that "nativeness" does not necessarily equate with being good a teacher just as "nonnativeness" means being a bad teacher. They also do not believe that students learn better from native English-speaking teachers (NEST) than NNESTs. What the supervisors expect from the nonnative speakers ALTs are clear pronunciation, correct grammar and good classroom management. They do agree however, that strong accent can be a problem since "strong accent means pronunciation problems". On one hand, the supervisors recommend that NNESTs should learn the Japanese language in order to communicate better with the Japanese students and teachers.

According to Lourd and Dennis, ALTs are required to learn basic Japanese. Other informants agreed that Japanese proficiency is important especially if they are assigned in elementary schools where the English proficiency of the students is very low or almost zero. However, according to Lourd, translations of the lessons from English of Japanese are usually done by the Japanese homeroom teacher. Although ALTs are allowed to use Japanese in the classrooms, they are not encouraged to do so. Dennis stressed that he uses Japanese as a last resort to make the students understand the lesson and to make the classroom livelier and more fun.

Postcolonial studies would attribute these views and perspectives to mimicry; the desire of the colonized to emulate the practices and cultural beliefs, including language of the colonizers. Because English in its standard varieties is seen as elusive, the belief that to sound native is an after effect, an ambivalent and impure colonial desire of longing to belong (Bhaba, 1994). Thus, Filipino ALTs see no problem in being pressured to sound native in the teaching of English in Japan where the long-held notion of nativeness and correctness is to sound American because it is the only way to be accepted and recognized in the system.

\section{Working Environment and "Nonnativeness"}

A number of informants share the view that the emphasis on their "nonnativeness" stem from their coworkers who are native speakers. This "othering" and the judging of performance based on the dichotomy of nativeness/nonnativeness is felt by Filipino ALTs around their NESTs colleagues. Irish and Lourd consider this treatment as discrimination.

They (NESTs) would correct our pronunciation or word use in front of other teachers. Their gestures, the way they talk, even blaming us for problems which are not our fault..it's really discrimination...

Lourd has also a similar experience. In a team teaching with a NEST, he was told to shut up in front of others during a meeting and during activities. This NEST would also correct his pronunciation and articulation of words. Irish, the ALT who has a $\mathrm{PhD}$ degree, agrees that this can happen sometimes. For her, it is important to counter this discrimination by working better and harder. This is also shared by other informants who claim that the advantage of Filipino ALTs over NESTs is their work habits and attitudes. These include coming to class early, working overtime when they think it is necessary and without being asked to do so, volunteering in sports activities, maintaining a cordial relationship with students, parents and coworkers. Lourd, who has been a victim of gossip from NESTs, which according to him is because of jealousy because he is the favorite of Japanese teachers and students, said that the real strength of Filipino ALTs is the drive to earn for their family. While NESTs see the ALT program as a pastime and a diversion from their lives in their countries of origin, the Filipino ALTs consider their teaching as a respectable profession and an opportunity to make their and their family lives' in the Philippines much better. He added that NESTs are only accepted as ALTs because they are native speakers.

These strategies of countering discrimination may have worked and made an impression to JETs. Although Filipino ALTs may need to improve on their grammar and pronunciation, the Japanese supervisors interviewed attest that they are very good in classroom management, interpersonal communication with their colleagues and student motivation. According to one of the Japanese teachers who answered the detailed questionnaire:

They (Filipino ALTs) are able to understand the characteristics of Japanese, they fit the demands here. They are extremely thorough. They adapt to the educational strategy and method here. They also provide specific support for/of Japanese teachers of English language, such as scoring tests, preparing teaching materials, and practicing speech.

Likewise, they can be highly dependable and creative in handling their classes. Thus, this counter discrimination acts by ALTs can be seen as a strategy to be accepted in the work place and to reconfigure their notions of what it means to be a teacher within the domain of the ALT system.

More importantly, frustrations can be gleaned from the Filipino ALTs on how English teaching and learning program is being implemented in Japan. They believe that the JET Program may be effective in its internationalization efforts but not in developing the intercultural competence and the language proficiency of the Japanese students. Seen from the perspective of a people who have imbibed the language and made it part of their daily communication, the Filipino ALTs agree that the Japanese educational system should create more opportunities for students to use English, emphasize to them the need for English proficiency and loosen its fixation on sounding like native speakers. What is 
more frustrating for them is that these views do not have any influence on how the program is implemented since their tasks and roles as ALTs are already clearly defined.

These adjustments and exerting more efforts on the part of Filipino ALTs to make up for their nonnativeness repudiate their contributions and qualifications as NNESTs. The focus on nativiness in teaching English as a foreign language trivializes their abilities, fosters discrimination and to a certain extent unfair work practices.

\section{CONCLUSION}

The dichotomy of nativeness/nonnativeness in the teaching and learning of English in Japan brings forth the sociopolitical implications of the JET Program, its inadequacies and how the processes of globalization intersects and influences the spread, particularly, the teaching and learning of English.

Nonnativess therefore, within the context of Filipino ALTs in Japan is a reconfiguration of identity and a fulfillment of desires and longing tied to language use and power. These require NNESTs to sound native, to put extra effort of work, face and counteract perceived forms of discrimination in order to be accepted in the work system imposed on them by the host country. Contrary to what the program aims, the Filipino ALTs do not feel empowered to help in the internationalization of Japan nor spread the use of English in the country. Despite the fact that their motivations to become ALTs hinge largely on economic gains and social mobility, the Filipino ALTs are aware of their responsibilities as teachers in a country that is not so receptive to the use of the language. However, they are limited and constrained by the Japanese ideological view on nativeness, thus repudiating their roles as teachers and precursors of the spread and use of the English language in Japan. Their experiences, particularly as ALTs and NNESTs pave the way for the interrogation of language ideologies such as nativeness and how it affirms Pennycook's claim that language learning, particularly English, is an intersectionality of the forces of globalization, local contexts and postcolonial ethos such as longing, desire and acceptance.

\section{ACKNOWLEDGMENTS}

The author wishes to thank Sumitomo Foundation of Tokyo, Japan for the financial support in the conduct of this study and to the Filipino ALTs for their time and trsut.

\section{REFERENCES}

[1] Bhabha, H. (1994). The location of culture. New York: Routledge.

[2] Ballescas, C. (2009). Filipino ALTs in Japan. Philippine Star. https://www.philstar.com/opinion/2010/10/14/620500/filipinoalts-japan (accessed 01/10/2018)

[3] Bernardo, A.(2008). English in Philippine education: Solution or problem. https://www.academia.edu/2323946/English_in_Philippine_education_Solution_or_problem?auto=download （accessed 02/10/2018).

[4] Bruthiaux, P. (2003). Squaring the circles: issues in modeling English worldwide. International Journal of Applied Linguistics 13.2, 159-178.

[5] Holliday, A. (2006). Native speakerism. ELT Journal 60.1, 385-387.

[6] Honna, N. \& Takeshita, Y. (1998). On Japan's propensity for native speaker English: A change in sight. Asian Englishes 1.1, 117-134.

[7] Kabel, A. (2008). Native-speakerism, stereotyping and the collusion of applied linguistics. System 37, 12-22.

[8] Kachru, B. (1991). World Englishes and Applied Linguistics. In Tickoo, Makhan., Eds. Languages and Standards: Issues, Attitudes, Case Studies, 178-195.

[9] Kaur, P. (2013). Attitudes towards English as a Lingua Franca. Procedia - Social and Behavioral Sciences 118, 214 - 221.

[10] Kobayashi, Y. (2001). The learning of English at academic high schools in Japan: Students caught between exams and internationalization. Language Learning Journal 23, 67-62.

[11] Hayes, D. (2008). Non-native English-speaking teachers, context and English language teaching. System 37, 1-11.

[12] Jenkins, J. (2006). Current Perspectives on Teaching World Englishes and English as a Lingua Franca. TESOL Quarterly 40. 1, $157-181$.

[13] Jenkins, J. (2007). English as a Lingua Franca: attitude and identity. Oxford: Oxford University Press.

[14] Martin, I. (2014). Philippine English revisited. World Englishes 33.1, 50-59.

[15] McRostie, J. (2017). As Japan's JET Programme hits its 30s, the jury's still out. Japan Times. https://www.japantimes.co.jp/community/2017/05/03/issues/japans-jet-programme-hits-30s-jurys-still/\#.W8KU2i2B2JI (accessed 01/10/2018).

[16] McWhorter, J. (2015). How immigration changes language: The invention of new ways of speaking is one surprising consequence of migration to Europe. The Atlantic https://www.theatlantic.com/international/archive/2015/12/languageimmigrants-multiethnolect/420285/ (accessed 14/12/2017).

[17] Mesthrie, R. (2010). New Englishes and the native speaker debate. Language Sciences, 32, 594-601.

[18] Moussu, L and. Llurda, E. (2008). Non-native English speaking English language teachers: History and Research. Language Teaching Cambridge 41.3, 315-348.

[19] Ohtani, C. (2010). Problems in the Assistant language teacher system and English activity at Japanese Public elementary schools. Educational Perspectives 43.1.2, 57-86.

[20] Pennycook, A. (2017). The cultural politics of English as an international language. New York: Routledge. 
[21] Pennycook, A. (1998). English and the discourses of colonialism. London: Routledge.

[22] San Jose, B. \& M.R. Ballescas. (2010). Engaging multiculturalism from below: The case of Filipino ALTs in Japan. Journal of Asian Studies for Intellectual Collaboration, 162-178.

[23] Scholefield, W. (1996). What do JTEs really want? Swenson, Tamara. Ed. Japan Association for Language Teaching 18.2, 726.

[24] Solano-Campos, A. (2014). The making of an international educator: Transnnationalism and Nonnativeness in English teaching and learning. TESOL Journal, 5.3, 412-439.

[25] Sponseller, A. (2016). Role Perceptions of JTEs and ALTs engaged in team teaching in Japan. https://ir.lib.hiroshimau.ac.jp/files/public/4/42781/20170419113008205309/HiroshimaJSchEduc_23_123.pdf (accessed 30/06/2018).

[26] The Japan and Exchange Teaching Programme. http://jetprogramme.org/en/positions/ (accessed 01/10/2018).

Nelia G. Balgoa. Doctor in Human Sciences (2011) from the School of Human Sciences of Osaka University, Osaka, Japan. MA(2002) in Language and Culture from Osaka University of Foreign Studies, Osaka, Japan and BA (1994) in English from the Mindanao State University-Marawi. She is currently a professor in the Department of English where she teaches Language and Culture, Semiotics, in both the undergraduate and graduate programs. Her research interests include Philippine Migration, Philippine Literature and Transnationalism Studies. 